\title{
STRATA NORMA PUISI-PUISI W.S RENDRA DALAM KUMPULAN PUISI DOA UNTUK ANAK CUCU SEBAGAI BAHAN AJAR SASTRA DI SMA DAN MODEL PEMBELAJARANNYA
}

\author{
Rustam Effendi \\ e-mail:r.effendi12@yahoo.co.id
}

\begin{abstract}
Abstrak
Penelitian ini bertujuan: (1) mendeskripsikan strata norma puisi-puisi W.S. Rendra dalam kumpulan puisi Doa untuk Anak Cucu; (2) mendeskripsikan kelayakan puisi-puisi W.S. Rendra dalam kumpulan puisi Doa untuk Anak Cucu sebagai bahan pembelajaran apresiasi sastra di SMA; dan (3) membuat model pembelajaran yang tepat untuk pembelajaran puisi W.S Rendra dalam kumpulan puisi Doa untuk Anak Cucu. Metode yang digunakan dalam penelitian ini yaitu deskriptif kualitatif, yang berarti data dan hasil analisisnya berbentuk deskriptif kualitatif. Teknik pengumpulan data dilakukan dengan cara membaca dengan teliti puisi-puisi W.S. Rendra kemudian menandai kata-kata yang mengandung strata norma. Data yang diperoleh dianalisis kelayakannya untuk menjadi bahan pembelajaran bahasa di SMA, selanjutnya menerapkannya melalui model pembelajaran yang terpilih.

Hasil penelitian ini dapat di simpulkan bahwa dari kesepuluh puisi dalam kumpulan puisi Doa untuk Anak Cucu karya W.S.Rendra, terdapat berbagai lapis yang ada dalam strata norma, yaitu (1) penggunaan lapis bunyi, rima atau irama yang seimbang. (2) penggunaan majas yang beragam dalam lapis arti pada

puisi W.S. Rendra meliputi majas hiperbola, personifikasi, perumpamaan dan repetisi. (3) lapis ketiga yaitu rangkaian satuan-satuan arti berupa latar, pelaku, dan objek-objek yang juga cara penggunaannya beragam. (4) lapis dunia yang berkaitan dengan pencitraan, terdapat citraan penglihatan (visual), pendengaran (audio), dan rabaan (taktil). Ketiga citraan tersebut digunakan dalam kesepuluh puisi secara seimbang. (5) lapis metafisis atau tema yang diguanakan sangat beragam, seperti tema sosial politik, sejarah dan keagamaan. Puisi W.S.Rendra dapat dijadikan sebagai alternatif bahan pembelajaran di SMA meliputi bahasa, psikologi, dan latar belakang budaya. Model pengajaran investigasi kelompok menjadi alternatif model yang baik untuk bahan pembelajaran puisi-puisi W.S. Rendra.
\end{abstract}

Kata Kunci : strata norma, puisi, bahan ajar, dan model investigasi kelompok

\section{A. PENDAHULUAN}

Puisi sebagai salah satu jenis sastra merupakan pernyataan paling inti dan sarat akan makna. Dibandingkan dengan karya sastra lainnya, puisi merupakan karya sastra yang tidak mudah untuk dipahami, memerlukan konsentrasi yang lebih untuk membacanya. Puisi dapat dikaji dari berbagai aspeknya, mulai dari unsur-unsurnya, ragamnya, maupun kesejarahannya. Dengan mengkaji puisi dapat diketahui makna dan perasaan seorang pengarang ketika menulis puisi tersebut. Mengkaji puisi tidaklah mudah, tapi tidak juga begitu sulit, dalam upaya memahami teks sastra, terutama puisi, kesulitan utama yang biasa muncul adalah dalam upaya memahami makna. Richards (dalam Pradopo, 2012: 12 ) mengungkapkan, the original difficulty of all reading, the 
problem of making out the meaning, is our obvious starting- point.

Puisi sebagai slah satu Karya sastra itu tak hanya merupakan satu sistem norma, melainkan terdiri dari beberapa strata ( lapis) norma. Tiap-tiap norma menimbulkan lapis norma di bawahnya. Wellek (dalam Pradopo, 2012: 14) mengemukakan analisis Roman Ingarden, seorang filsuf Polandia, di dalam bukunya Das Literarische Kunstwerk (dalam pradopo, 2012: 14) menganalisis normanorma itu sebagai berikut.

Lapis norma pertama adalah lapis bunyi (sound stratum). Bila orang membaca puisi yang terdengar itu ialah rangkaian bunyi yang dibatasi jeda pendek, agak panjang, dan panjang. Akan tetapi, suara itu bukan hanya suara tak berarti. Suara sesuai dengan konvensi bahasa, disusun begitu rupa hingga menimbulkan arti. Lapis arti (units of meaning) berupa rangkaian fonem, suku kata, kata, frase, dan kalimat. Semuanya itu merupakan satuan-satuan arti. Rangkaian satuan-satuan arti ini menimbulkan lapis ketiga , yaitu berupa latar, pelaku, objekobjek yang dikemukakan, dan dunia pengarang yang berupa cerita atau lukisan. Lapis dunia yang dipandang dari titik pandang tertentu yang tak perlu dinyatakan, tetapi terkandung di dalamnya (implied). Lapis metafisis, berupa sifat-sifat metafisis ( yang sublim, yang tragis, mengerikan atau menakutkan, dan yang suci), dengan sifatsifat ini seni dapat memberikan renungan (kontemplasi) kepada pembaca. Akan tetapi, tidak setiap karya sastra di dalamnya terdapat metafasis seperti itu.

Karya sastra khsususnya puisi umumnya diajarkan dalam proses pembelajaran pada jenjang pendidikan SMA. Pembelajaran puisi sebenarrnya salah satu materi pembelajaran sangat menarik khusus dalam menganalisis unsur yang terdapat dalam puisi tersebut. Untuk mencapai keberhasilan diperlukan alternatif pembelajaran yang dapat menarik peserta didik. Hal ini dimaksudkan agar para peserta didik mengetahui bagaimana unsurunsur yang terkandung dalam puisi W.S. Rendra dalam kumpulan puisi Doa untuk Anak Cucu dengan cara menggali unsur- unsur puisi tersebut sehingga para siswa mendapatkan pengalaman yang bernilai positif, menambah wawasan, mengetahui hal-hal yang patut untuk dijadikan sebagai pembelajaran bagi kehidupan siswa.

Bahan ajar yang lebih aktual dapat memberikan daya tarik lebih kuat pada siswa. Apalagi teknik yang digunakan guru dalam menyampaikan materi pelajaran sangat menarik dan berkembang, tentunya siswa dapat berimajinasi yang menyenangkan. Terkadang bahan pengajaran yang disajikan guru kurang aktual. Hal ini berakibat siswa bosan, karena guru kurang kreatif dan inovasi dalam pengajaran sastra sehingga peserta didik tidak mempunyai wawasan yang luas dalam memahami dan menanggapi berbagai macam situasi kehidupan.

Pemilihan kegiatan pembelajaran ini bertujuan agar tecapai secara keseluruhan. Karena itu, guru dituntut terampil dalam memilih bahan pengajaran untuk siswanya. Pemilihan bahan pengajaran yang tepat merupakan langkah perencanaan guru untuk mempersiapkan kegiatan belajar mengajar. Rooijakkers (dalam Sagala, 2013: 174) mengemukakan bahwa keberhasilan seorang pengajar akan terjamin, jika pengajar itu dapat mengajak para muridnya mengerti suatu masalah melalui semua tahap proses belajar, karena dengan cara begitu murid akan memahami hal yang akan diajarkan. Dengan begitu dalam proses pembelajaran seorang guru harus memilih model yang sesuai dengan materi yang akan diajarkannya.

Pada akhirnya kegiatan belajar mengajar perlu dilihat dari hasil nyata dengan cara mengadakan evaluasi sebagai tolak ukur keberhasilan kegiatan belajar mengajar. Akan tetapi kenyataan yang ada proses belajar mengajar sastra sering kali dilupakan atau hanya sekedar di ajarkan tanpa mendalami materi tentang sastra tersebut, sehingga menjadi permasalahan dalam penyebaran minat sastra terhadap siswa di sekolah.

Oleh karena itu dalam proses belajar mengajar, guru harus aktif dengan cara 
memahami dan mencari karya sastra terbaru sebagai media pembelajaran sastra di sekolah, selain memperhatikan materi yang akan diajarkan, guru juga harus mengetahui kemampuan dasar yang dimiliki siswa, hal ini berkaitan dengan minat siswa terhadap suatu materi yang diajarkan guru. Menurut Sagala (2013: 61) proses pembelajaran pada awalnya meminta guru untuk mengetahui kemampuan dasar yang dimiliki oleh siswa meliputi kemampuan dasar, motivasi, latar belakang, akademis, latar belakang sosial ekonomi, dan lain sebagainya. Kesiapan guru untuk mengenal karakteristik siswa dalam pembelajaran merupakan modal utama penyampaian bahan belajar dan menjadi indikator suksesnya pelaksanaan pembelajaran.

Skripsi ini akan membahas strata norma pada puisi-puisi W.S. Rendra dalam kumpulan puisi Doa untuk Anak Cucu. Hal-hal yang akan dikaji dalam puisi tersebut adalah struktur strata norma serta model pembelajarannya.

\section{B. KAJIAN TEORI \\ Strata Norma}

Strata norma adalah tahap atau lapis untuk menganalisis karya sastra yaitu puisi, lapis tersebut terdiri dari lapis bunyi, lapis arti, lapis satuan arti, lapis dunia, dan lapis metafisis. Wellek (dalam Pradopo, 2012: 14) mengemukakan analisis Roman Ingarden, bahwa setiap norma dalam sebuah analisis puisi menimbulkan lapis norma di bawahnya yaitu lapis bunyi, lapis arti, lapis satuan arti, lapis dunia, dan lapis metafisis.

\section{Pengertian Puisi}

Puisi merupakan ekspresi pemikiran yang membangkitkan perasaan, yang merangsang imajinasi panca indera dalam susunan yang berirama, semua itu merupakan sesuatu yang penting, yang direkam dan diekspresikan, dinyatakan dengan menarik dan memberi kesan. Puisi itu merupakan rekaman dan interpretasi pengalaman manusia yang penting, digubah dalam wujud yang paling berkesan (Pradopo, 2012: 7).
Sebagai karya seni, puisi merupakan pelajaran bagi pembaca dan dapat dinikmati sebagai bahan referensi serta analisis. Melalui bahasa, puisi mudah dipahami dan dicerna oleh para pembaca. Puisi juga dapat dijadikan sebagai bahan analisis sebuah penelitian yang meneliti tentang sebuah puisi tertentu.

Hudson (dalam Aminuddin, 2014: 134) mengungkapkan bahwa puisi adalah salah satu cabang sastra yang menggunakan kata-kata sebagai media penyampaian unuk membuahkan ilusi dan imajinasi, seperti halnya lukisan yang menggunakan garis dan warna dalam menggambarkan gagasan pelukisnya.

\section{Metode Investigasi Kelompok}

Metode pembelajaran Investigasi Kelompok atau Group investigation mengambil model dari masyarakat, terutama mengenai mekanisme sosial yang ada pada masyarakat yang biasa dilakukan melalui kesepakatan bersama. Proses belajar pada hakikatnya adalah mengadakan hubungan sosial dalam pengertian siswa berinteraksi dengan siswa lain dan berinteraksi dengan kelompoknya (Sagala, 2013: 179).

Model Group investigation seringkali disebut sebagai metode pembelajaran kooperatif yang paling kompleks. Hal ini disebabkan oleh metode ini memadukan beberapa landasan pemikiran, yaitu berdasarkan pandangan konstruktivistik, democratic teaching, dan kelompok belajar kooperatif.

\section{METODOLOGI PENELITIAN}

Metode yang digunakan dalam penelitian ini adalah metode deskriptif kulaitatif. Penulis memilih metode ini karena sumber datanya sudah tersedia tanpa harus melakukan perlakuan (treatment). Dengan menggunakan metode deskriptif, seorang peneliti sastra dituntut mengungkap faktafakta yang tampak atau data dengan cara memberi deskripsi. Fakta atau data merupakan sumber informasi yang menjadi basis analisis. Tetapi data harus diambil berdasarkan parameter yang jelas 
(Siswantoro, 2008: 57). Berdasarkan metode tersebut, penulis memfokuskan menganalisis pada salah satu karya sastra yaitu puisi karya W.S. Rendra dalam kumpulan puisi Doa Untuk Anak Cucu.Metode ini untuk menganalisis strata norma yang terdapat dalam kumpulan puisi Doa Untuk Anak Cucu karya W.S. Rendra, sebagai bahan pembelajaran dan model pembelajaran di SMA.

\section{HASIL DAN PEMBAHASAN}

Pembahasan Hasil Analisis Strata norma pada kumpulan puisi "Doa Untuk anak Cucu" karya W.S. Rendra

\section{Lapis Bunyi}

Dari hasil analisis ke 10 puisi karya W.S. Rendra keseluruhan puisi tersebut banyak menyisipkan rima. Seperti puisi-puisi lainnya, W.S. Rendra memberikan kesan kekhasan pada puisi-puisi yang dibuatnya dengan menyisipkan rima. Selain untuk dapat mengungkapkan perasaan yang akan disampaikan penulis, rima juga berfungsi untuk dapat mencari kejelasan kesan serta kemerduan puisi itu. Seperti dalam puisi "ibu di Atas Debu", terdapat pada bait pertama yaitu adanya paduan bunyi antara setiap akhir larik sehingga menimbulkan pola persajakan vokal (u) seperti "termangu", "berdebu", "serdadu", "ibu", "di situ", dan "tunggu". Selain pengulangan vokal (u) terdapat pula pengulangan konsonan (n) pada kata "hutan" dan "lautan".

Selain pada puisi "Ibu di Atas Debu" lapis bunyi juga terdapat pada beberapa puisi lainnya contohnya yaitu pada judul puisi "Sagu Ambon" yaitu pada kalimat "Pohonpohon pala di bukit sakit" dan baris "Burung-burung nuri menjerit". Pengulangan bunyi pada akhir dalam baris puisi tersebut "sakit" dan "menjerit" sama-sama menggunakan akhiran "it", sehingga menimbulkan nada yang serasi ketika puisi itu dibacakan.

\section{Lapis arti}

a. Pemajasan

Hampir ke-10 puisi W.S. Rendra yang telah dianalisis di dalamnya menggunakan pemajasan, berikut beberapa majas yang digunakan pada lirik-lirik lagu Raisa.

1) Majas personifikasi

Pemajasan yang banyak digunakan yaitu majas personifikasi seperti pada puisi "Sagu Ambon" yaitu pada bait "Burung-burung nuri menjerit"dan pada bait "Pohon-pohon kelapa berdansa" juga pada bait "Bumi meratap dan terluka". Ketiga bait tersebut menggunakan perumpamaan pada benda selain manusia dengan memberikan sifat dan sikap manusia pada benda-benda tersebut.

2) Majas perumpamaan

Tidak hanya majas personifikasi, majas perumpamaan juga banyak sekali digunakan oleh penulis agar puisinya lebih menarik. Contohnya pada puisi "Sagu Ambon" pada bait "Air mata kita menjadi tinta sejarah", mengumpamakan air mata sebagai tinta dilatar belakangi oleh sebuah keadaan yang tidak menyenangkan dan kesedihan yang telah banyak dilalui manusia sehingga menjadi pelajaran hidup yang masih dipelajari samapi sekarang untuk dijadikan sebuah cerminan.

3) Majas hiperbola

Pada puisi "Ibu di Atas Debu" terdapat majas hiperbola pada bait ke-2 dan ke- 4 "Jakarta menjadi lautan api" dan "mayat menjadi arang" dalam larik tersebut terdapat majas hiperbola karena kata-katanya mengandung pernyataan yang berlebih-lebihan dengan maksud untuk memperhebat atau meningkatkan kesan dan pengaruh pada arti puisi tersebut.

\section{4) Majas repetisi}

Terdapat beberapa majas repetisi yang digunakan penulis dalam puisinya sepertisi pada puisi "Jangan Takut Ibu" Terdapat majas repetisi pada awal bait yaitu pada larik "Matahari musti terbit", dan "Matahari musti mati". Penggunaan kata "matahari" yang diulang dalam puisi tersebut adalah sebagai penegasan.

\section{b. Diksi}

Diksi merupakan pilihan kata yang digunakan untuk memperindah dan juga agar puisi tersebut memiliki banyak makna dengan kata yang sedikit. Pemilihan kata dalam ke- 10 puisi ini banyak menggunakan 
kata-kata yang indah dan kaya akan makna sehingga sedikit sulit untuk di mengerti.

tersebut dinilai memiliki kesaratan makna dan juga indah.

\section{Lapis ketiga berupa latar, pelaku,} dan alur

Dalam ke-10 puisi yang dianalisis memiliki latar yang berbeda, dari yang berjudul puisi "Ibu di Atas debu" mempunyai latar tentang sosial dimana dalam puisi ini menceritakan nasib seorang ibu yang terlantar, kehilangan tempat tinggal, kehilangan seorang anak, dan kehilangan belas kasihan dari pemerintah.

Latar politik juga digambarkan pada beberapa puisi yaitu, "Sajak Bulan Mei 1998 di Indonesia" yang menerangkan tentang sebuah tempat, kejadian yang terjadi di lingkungan politik. Pelaku yang tersirat pada puisi "Sajak Bulan Mei 1998 di Indonesia" yaitu orang-orang yang berada di lingkungan politik, seperti para politikus itu sendiri.

Selain latar politik, keagamaan juga melatarbelakangi isi dari puisi-puisi W.S. Rendra. Seperti, latar dalam puisi "Gumamku, ya Allah" yaitu tentang keagamaan dimana seorang mausia yang diciptakan sama seperti manusia yang lainnya, mempunyai pertanyaan yang sama yaitu seperti apa yang menciptakan mereka? Dalam puisi itu diceritakan si pelaku mengalami kebingungan. Dalam puisi "Doa" ini berlatarkan keagamaan, yang lingkupnya mengenai banyak hal dalam agama, seperti kepercayaan akan muzijat, kepercayaan tentang kebenaran yang diajarkan agama itu pada pelaku yang ada di dalamnya. Pelaku yang tersirat dan tersurat pada puisi "Doa" ini merupakan perwujudan seorang hamba, yang digambarkan dalam kata "aku", yang tengah memohon hal-hal kebaikan pada tuhan yang disebutkannya dalam puisi itu.

Berbeda dengan kedua latar puisi-puisi yang telah di sebutkan diatas, puisi-puisi berikut mengandung latar sejarah. Yaitu, dalam puisi "Maskumambang", karena puisi tersebut menceritakan orang tua yang sedang menceritakan kehidupannya dulu dan membandingkannya dengan kehidupan sekarang. Puisi "Sagu Ambon" juga memliki latar sejarah yaitu berupa sebuah kejadian nyata yang terdapat di kota Ambon yang kemudian mendasari adanya sebuah sejarah terjadinya banyak kejadian-kejadian yang kurang menyenangkan.

\section{Lapis Dunia}

Lapis ini adalah lapis yang keempat yaitu lapis dunia yang dipandang dari titik pandang tertentu yang tak perlu dinyatakan, tetapi terkandung di dalamnya (implied). Lapis dunia juga dapat dikatakan sama dengan pencitraan. Ada tiga macam pencitraan yaitu, cintraan penglihatan, citraan pendengaran, dan citraan rabaan/sentuhan. Hampir dari ke-10 puisi yang dianalisis mengandung pencitraan.

1) Citraan penglihatan

Citraan penglihatan merupakan citraan yang mengggunakan dengan indera penglihatan seperti pada puisi "Ibu di Atas Debu" pengkonktretan suatu objek diungkapkan pada bait "wajahnya bagai sepatu serdadu", dan pada bait "tak jelas menatap apa".

2) Citraan Pendengaran

Citraan yang terdapat pada puisi "Ibu di Atas Debu" terdapat pada kalimat yang jenis pengonkretan melalui sesuatu yang berhubungan dengan pendengaran. Seperti pada larik "dengarlah suara batuk itu", kemudian pada puisi yang kedua "Sagu Ambon" citraan pendengaran tergambar pada kalimat "Dimana nyanyian anak-anak sekolah".

3) Citraan Rabaan

Citraan yang menunjuk pada sesuatu yang pengonkretannya hanya terjadi pada imajinasi pembaca, dan dalam puisi "Ibu di Atas Debu" citraan rabaan tergambar pada kalimat "kenapa kamu duduk di situ?" dan "seperti ketukan lemah di pintu. Citraan rabaan pada puisi "Sagu Ambon" tersirat pada kalimat "lebih baik kita bakar sagu saja". Pada puisi "Sajak Bulan Mei 1998 di Indonesia" citraan rabaan tergambar pada larik "Air mata mengalir dari sajakku".

\section{Lapis Metafisis}

a. Tema

Pada lapis ini akan di jelaskan tentang tema dan pesan yang terdapat pada puisi-puisi yang telah dianalisis. Tema pada ke-10 puisi 
yang dianalisis sangat beragam contoh pada puisi yang pertama yaitu "Ibu di Atas Debu" mencerminkan tema tentang sebuah Negara yang para pemimpinnya menelantarkan rakyatnya.

Tema dalam puisi "Gumamku, ya Allah" bertemakan keagamaan karena penyair dalam puisinya membicarakan tentang ciptaan-ciptaan sang pencipta, agama, doa dan puja.

\section{b. Amanat/pesan}

Pada ke-10 puisi W.S. Rendra yang dianalisis semuanya memiliki pesan yang dapat kita jadikan gambaran dalam menjalani kehidupan agar lebih baik. Amanat yang terdapat dalam puisi " Ibu di Atas Debu" menganjurkan kita agar tidak egois (mementingkan diri kita sendiri) tanpa memerhatikan orang lain di sekitar kita. Pada puisi "Sagu Ambon" ini yaitu mengajak kita untuk saling menghormati dan menyayangi antara satu dan yang lain. Dan menegaskan bahwa permusuhan hanya akan merugikan semua pihak.

\section{E. SIMPULAN}

Berdasarkan hasil penelitian, simpulan yang diperoleh sebagai berikut.

1) Strata norma pada kesepuluh puisi dalam kumpulan puisi "Doa untuk Anak Cucu" karya W.S.Rendra yang telah dianalisis memiliki lapis-lapis yang terdapat dalam strata norma, yang pertama yaitu lapis bunyi, kesepuluh puisi yang telah dianalisis memiliki lapis bunyi yang beragam, seperti rima vertikal dan rima horizontal. Kesepuluh puisi ini menggunakan rima dan irama yang seimbang, baik rima vertikal dan rima horizontal. Lapis yang kedua, yaitu lapis arti, berkaitan dengan penggunan majas. Kesepuluh puisi ini menggunakan majas yang beragam, seperti majas personifikasi, hiperbola, perumpamaan, dan repetisi. Lapis ketiga, yaitu rangkaian satuan-satuan arti berupa latar, pelaku, dan objek-objek. Pada lapis ini pengarang menunjukkan sebuah latar atau tempat kejadian yang ada dalam puisi, seperti pada puisi "Ibu di Atas
Debu" merupakan gambaran keadaan kota Jakarta yang menjadi lautan api. Selain kota, dalam puisi "Sagu Ambon" pengarang menggunakan latar di atas bukit dan lautan. Masih banyak latar yang beragam yang ada pada kesepuluh puisi yang telah dianalisis. Selain latar ada pula pelaku yang terdapat dalam kesepuluh puisi ini seperti dalam puisi "JanganTakut Ibu". Puisi itu menjelaskan seorang ibu yang ketakutan. Lapis keempat, yaitu dunia yang berkaitan dengan pencitraan. Kesepuluh puisi ini menggunakan beragam pencintraan yaitu citraan penglihatan (visual), pendengaran (audio), dan rabaan (taktil). Semua penggunaan citraan tersebut seimbang, semuanya ada dalam kesepuluh puisi yang telah dianalisis. Lapis yang terakhir yaitu lapis metafisis atau menjelaskan tema dan amanat yang terkandung dalam puisi. Kesepuluh puisi yang telah dianalisis menggunakan tema yang beragam, seperti tema politik, keagamaan dan sejarah.

2) Berdasarkan kriteria bahan pembelajaran pada kriteria bahasa penggunaan gaya bahasa pada dalam kumpulan puisi "Doa Untuk Anak Cucu” karya W.S. Rendra dapat menjadi contoh yang baik untuk gaya bahasa remaja masa kini. Sedangkan pada kriteria psikologi, puisi W.S.Rendra menggambarkan psikologi, sifat, dan sikap yang baik untuk menjadi cerminan para peserta didik. Demikian juga pada kriteria latar belakang budaya. Penggunaan gaya bahasa yang baik dan sopan pada puisi W.S. Rendra menggambarkan sikap, sifat dan kebiasaan yang baik untuk dapat dijadikan contoh hidup yang baik dimasyarakat. Mengamati kesesuaian ketiga kriteria itu, maka puisi W.S. Rendra dapat menjadi salah satu alternatif bahan pembelajaran di SMA pada kompetensi dasar menganalisis sebuah teks.

3) Model pembelajaran yang digunakan dalam pembelajaran puisi karya W.S.Rendra dalam kumpulan puisi "Doa 
BAHTERA INDONESIA:

ISSN 2541-3252

Jurnal Penelitian Pendidikan Bahasa dan Sastra Indonesia

Vol. 2, No. 1, Mar. 2017

Untuk Anak Cucu” menggunakan model Investigasi kelompok (Group

Investigation). Model pembelajaran ini dapat membuat peserta didik lebih aktif dan lebih leluasa untuk berinteraksi dalam proses pembelajaran. Karena model ini dilandasi dengan nilai-nilai demokrsai yaitu penghargaan, terhadap kemampuan, menunjang keadilan, dan memperhatikan keberagaman peserta didik.

\section{DAFTAR PUSTAKA}

Aminuddin. 2013. Pengantar Apresiasi Karya sastra. Bandung: Sinar Baru Algensindo.

Aqip Zainal. 2013. Model-model, Media, dan

Strategi Pembelajaran Konstektuan (Inovatif). Bandung: Yrama Widya.

Gunawan, Imam. 2013. Metode Penelitian Kualitatif; Teori dan Praktik. Jakarta : Bumi Aksara.

Joyce, Weil, dan Calhoun. 2011. ModelModel Pengajaran. Yogyakarta: Pustaka Pelajar.

Kosasih, E. 2012. Dasar-Dasar Keterampilan Bersastra. Bandung: YramaWidya.

Maryati dan Sutopo. 2008. Bahasa dan Sastra Indonesia. Jakarta: Pusat Perbukuan.

Minderop, Albertine. 2010. Psikologi Sastra. Jakarta : Yayasan Pustaka Obor Indonesia.

Pradopo. 2012. Pengkajian Puisi. Yogyakarta: Gadjah Mada University Press.

Rahmanto, B. 1988. Metode Pengajaran Sastra. Yogyakarta: Kansius.

Rendra. 2013. Doa untuk Anak Cucu. Yogyakarta: Bentang pustaka.

Sagala, Syaiful. 2013. Konsep dan Makna Pembelajaran. Bandung: Alfabeta.

Suprijono. 2010. Cooperatif Learning. Yogyakarta: Pustaka Pelajara.

Toyidin. 2013. Sastra Indonesia Puisi Prosa Drama. Subang: Pustaka Bintang. 